\title{
Modeling institutional evolution
}

\author{
Bilin Neyapti * \\ Bilkent University, Department of Economics, 06800 Bilkent, Ankara, Turkey
}

\section{A R T I C L E I N F O}

Article history:

Received 10 April 2012

Received in revised form 25 April 2012

Accepted 15 May 2012

\section{Keywords:}

Institutional evolution

Punctuated path

Growth

\begin{abstract}
A B S T R A C T
This paper proposes a formal framework to analyze the process of institutional evolution in relation with economic progress. Institutions have both formal $(F)$ and informal $(N)$ aspects that may exhibit varying processes of change. $N$ is hypothesized to evolve with the level of capital stock, as in learning by doing, whereas $F$ is chosen optimally by a government that maximizes output subject to social and political costs. $F$ and $N$ together define the production technology and affect the income level. Consistent with evidence, simulations of the model's solution reveal that optimum $F$ exhibits a punctuated pattern.
\end{abstract}

(C) 2012 Elsevier B.V. All rights reserved.

\section{Introduction}

Institutions are defined as commonly accepted rules of the game and their enforcement mechanisms that result from repeated human interactions (North, 1990). The intertwined nature of the relationship between institutions and economic performance has become a key focus of the new development economics literature. ${ }^{1}$ This study offers a formal framework to analyze this relationship in view of the two prominent approaches to institutional economics: transaction cost and collective action theories. The former of these has been pioneered by Coase (1960) and developed as New Institutional Economics (NIE) by Williamson (1985) and North (1990) among others, while the latter is due to Olson $(1965,1982)$. The two approaches complement each other in understanding the nature of institutions in a given economy at a given period, as well as the factors that affect their evolution.

The transaction cost approach to institutional change focuses on the changes in productive factors and their relative prices that in turn influence the nature of institutional arrangements demanded by

\footnotetext{
* Tel.: +90 312290 2030; fax: +90 3122665140 .

E-mail address: neyapti@bilkent.edu.tr.

1 The examples are many, and include: Aron (2000), Clarke (2001), Cukierman et al. (1992, 2002), Dollar and Kraay (2003), Easterly and Levine (2003), Knack and Keefer (1995), and Rodrik et al. (2002), to name just a few prominent ones.
} 
society. According to this approach, institutions adapt both to each other and to the changing economic environment. Collective action theory, on the other hand, focuses on the circumstances that affect the formation and effectiveness of interest groups that facilitate institutional change via affecting governments' decisions. ${ }^{2}$ While the first approach provides an efficient view of institutional choice, collective action theory underlies the dynamics of institutional change, explaining the observed inefficiencies with regard to institutional change. ${ }^{3}$

In view of these two approaches, this paper models the formal and informal aspects of institutions in interaction both with each other and with economic progress. As technological accumulation and demographic evolution lead to changes in the means of production, social norms and traditional ways of doing business (informal institutions) continuously adapt to those changes, albeit slowly. When the evolution of informal institutions reaches a level that is not supported with the prevailing formal institutions, new interest groups emerge and support a change in legal frameworks. ${ }^{4}$ The prevailing formal structures have their powerful support groups, however, who would resist the change. Hence, all institutional changes resulting from these dynamics may not be Pareto improving.

Since formal institutional change is costly due to creative destruction, it is infrequent, although it may be abrupt and often inefficient due to the power struggle of interest groups. ${ }^{5}$ Olson (1982) calls this phenomenon institutional sclerosis and argues that it is a main factor in explaining the low growth rates in some stable democracies. ${ }^{6}$ As politicians face resistance from special interest groups, reforms may get delayed until the costs become too widespread and overwhelming, sometimes leading to crises. Institutions are usually reformed when their benefits exceed the cost of maintaining the existing ones on the aggregate. Political and economic crises that destroy the existing power-balances often generate an impetus for radical institutional reforms. ${ }^{7}$ Therefore, the pattern of institutional change is commonly observed to be punctuated.

In view of the foregoing, modeling institutional evolution should distinguish between two key attributes of a production technology: (i) the set of informal rules $(N)$ that is embedded in, or formed by, cultural or structural characteristics of a society and (ii) the set of formal rules $(F)$ that define the formal organizational characteristics of production. As production relations (proxied by $N$ ) evolve with the accumulation of the factors of production, as in learning by doing, changes in laws and regulations that organize those production relations $(F)$ may lag behind. The adoption of well-designed banking or competition laws and fiscal policy institutions are, for instance, often observed to lag behind the needs of an economy and usually follow a discontinuous pattern of development. $^{8}$

In addition to decisions resulting from domestic political processes, international advice or aidconditionalities of international organizations may also play a role in formal institutional changes. Many transition countries, for example, have adopted laws based on the experiences of developed countries (best-practice institutions), although they may not be consistent with domestic needs. Conflicts between legislations $(F)$ and existing informal rules $(N)$, however, have led to such reforms being dysfunctional in several cases. ${ }^{9}$ In the same spirit, both Boettke et al. (2008) and

\footnotetext{
${ }^{2}$ Coates and Heckelman (2003) and Coates et al. (2010, 2011) provide empirical evidence in support of Olson's theory. Heckelman (2007) provides a review of empirical tests of Olson's theory.

${ }^{3}$ See also Nabli and Nugent (1989).

${ }^{4}$ Kemmerling and Neugart (2009), for example, show the significant role of a developed financial sector on pension reforms in OECD.

${ }^{5}$ A future extension will be devoted to endogenizing the changes in the power structure in the economy to explicitly incorporate the collective action theory and thus the political economy perspective into the current model.

${ }^{6}$ According to Olson, stable democracies are most likely to accumulate special interest groups, leading to institutional inefficiencies of the kind later modeled in Acemoglu (2006).

${ }^{7}$ See, for example, Dincer and Neyapti (2008) for empirical evidence on the significant effect of crises on the adoption of banking laws.

${ }^{8}$ Competition law in Turkey, for example, was legislated more than a decade after its proposal, and more than 100 years after it was put into practice in the US.

${ }^{9}$ Transition economies, for instance, have adopted legislations that grant independence to their central banks or banking laws of developed countries at the onset of reforms in the early 1990s; those legislations, however, lacked the quality of implementability when they were not accompanied by other reforms (see Cukierman et al., 2002; Neyapti and Dincer, 2005).
} 
Williamson (2009) argue, and provide empirical evidence, that $N$ is a more dominant factor in explaining the development process than $F$, which needs to adapt to $N$ to have an impact on the level of development. ${ }^{10}$ Mathers and Williamson (2011), Williamson and Mathers (2011) and Williamson and Kerekes (2011) all point out the importance of distinguishing between $F$ and $N$, and report evidence regarding their dynamic interrelationship with each other and with economic development.

Although there have been a few recent attempts to model institutional change, the complexity of the dynamics involving its political and economic aspects leads these models to focus on specific aspects of institutional evolution. Foremost among them, Acemoglu (2006) develops a political economy model based on ex-ante characterizations of a middle class, workers and the elite who initially holds all the political power. He argues that inefficient policies result under both factor price manipulation and, though to a lesser extent, the revenue extraction incentives of the elite. In that model, a potential switch of political power towards the middle class also results in inefficient policy choices. Inefficient institutions result from the elite's desire to maintain these policies. Utilizing the implementation-theory framework to combine social choice with institutional economics, Yao (2004) also studies the issue of institutional efficiency. He finds that institutional change is sensitive to income distribution and sticky with respect to the economic environment; under several assumptions that define a good political process, efficient institutions are not implementable. ${ }^{11}$

The current study presents an original framework that utilizes capital accumulation and technology adoption to model the evolutionary pattern of $F$ and $N$. The model predicts a punctuated trajectory for $F$, which is consistent with the observed evolution patterns of various formal institutions. In what follows, Section 2 states the main thesis of this study. Section 3 outlines the formal model, followed by calibrations that are presented in Section 3.1. The findings of the model are compared to the empirical evidence in Section 3.2. Section 4 concludes.

\section{The hypothesis}

This paper argues that the evolution of formal institutions usually lags behind that of informal institutions; here, I specifically focus on the intrinsic process of institutional dynamics rather than externally guided or imposed changes that may reverse this phenomenon. As informal institutions change as a result of learning by doing, the process via which the organization of work changes as factors of production evolve and adapt to technology which in turn follows a continual progression, formal institutions change by legislations that are enacted by the government. Although formal institutions may hence change overnight, the frequency of major changes in them is relatively low.

In a democratic system, governments face some probability of replacement every election period and often focus on the demands of narrow constituencies rather than encompassing interests. ${ }^{12}$ Until the continuous progression in informal institutions leads to the emergence of new interest groups that gain political power to support formal institutional reforms, government policies are likely to accommodate the demands of existing interest groups to increase their reelection chances. For the sake of simplicity, the current model refrains from modeling political competition and interest group dynamics explicitly. To account for these dynamics implicitly, the cost of changing $F$ is assumed to depend on the state of the economy. In a political economy extension of this model, which is the subject of a future study, interest group dynamics will be modeled as a function of the state of the economy, incorporating the collective action approach explicitly into the model.

\footnotetext{
${ }^{10}$ Boettke et al. (2008) classify institutions as endogenous and exogenous, introduced by foreign and indigenous actors, and argue that indigenous-introduced endogenous institutions are stickier.

${ }^{11}$ Assumptions that define a good political process are Maskin monotonicity, the consideration of individual preferences only, no interpersonal utility comparison, and zero monetary transfers, the last of which is crucial for the reported finding.

${ }^{12}$ A government may only serve encompassing interests fully if it is a genuine mass party (or if it is a benevolent dictator).
} 
When there are powerful narrow interests that incur the (economic or political) costs of changing formal institutions, it takes time for politicians to respond to the needs building up for a change. Hence, rather than adjusting to the changes in $N$ every period, $F$ would exhibit a stepwise, or punctuated, change, occurring in a radical fashion that follows a period of stability. The notion of a punctuated evolutionary path follows from evolutionary biology (see Eldredge and Gould, 1972) that argues that species exist for an extended period (stasis) until they are somewhat abruptly replaced by other species (which has posed a challenge to Darwin's gradualist approach to evolution). The notion of institutions following a punctuated path has also been discussed or alluded to in the political science literature (see, for example, Mahoney, 2000; Pierson, 2000) and in organization theory (see Gersick, 1991), although it has not yet been modeled formally. ${ }^{13}$ The model proposed here has a potential to explicitly accommodate for various path-dependence views of institutional reproduction discussed in political science. Gersick further notes the uses of this theory in the explanations of scientific revolution, industrial innovation, organizational adaptation, adult development and in physics. In a similar vein, Roland (2004) likens the dynamics of institutional change to building tectonic pressures (in the form of growing inconsistency between $N$ and $F$ ), eventually giving way to a major earthquake (an abrupt change in $F$ ).

The main contribution of this paper is modeling formal institutional evolution in dynamic interaction with the economic growth process. Its main hypothesis is that, facing the costs of changing institutions that are associated with the changing preferences of interest groups, a government's objective of maximizing its net benefit results in a punctuated nature of (formal) institutional evolution.

\section{The model}

Consider a government that chooses the level of formal institutions $(F)$ optimally to maximize the level of output. In reality, it can be argued that each government has a specific constituency and optimally chooses $F$ both to serve its redistributive policies and to maximize its reelection chances, rather than to maximize output. The current model proposes a simple set up where it is assumed that each government cares about the whole society and assumes the entire cost of change to $F$; hence, the government type does not matter while the state of the economy does. This simplification is merely to focus on explaining the dynamics of institutional evolution. ${ }^{14}$

The production function is in its usual form, except that technology $(A)$ is composed of formal (legal) and informal institutions (norms), denoted by $F$ and $N$, respectively:

$$
y=A(F, N) f(k), \quad \text { where } A_{1,2}^{\prime}>0 ; \quad A_{1,2}^{\prime \prime}<0 ; \quad f^{\prime}>0 \text { and } f^{\prime \prime}<0
$$

where $y$ stands for per capita output and $k$ is capital per capita. North defines production as a process comprising both transformation and transaction. Accordingly, the way technology is expressed, $A(F$, $N$ ), reflects the transaction-cost reduction function of institutions. ${ }^{15}$ Thus, an increase in the institutional quality, indicated by higher values of $F$ and $N$, implies higher total productivity or lower transaction costs. ${ }^{16}$ Incorporating the role of institutions into the model in this fashion may appear

\footnotetext{
${ }^{13}$ In the context of organizational theory, Gersick argues that equilibrium is such a state that deep structures do not change for long periods while internal and external perturbations affect the system gradually. He also notes that:Prigogine and Stengers (1984, p. 207)... have argued that traditional deterministic paradigms have had "particularly unfortunate" effects on the social sciences. According to these authors, the search for optimizing, predictive trajectories that can be extrapolated to infinity is misguided because such approaches account neither for the extremes to which inertia may drive a system. ..., as Gould (1985) noted, efforts to unravel a system's workings by minutely dissecting its parts miss the point when the parts' behavior is determined by the deep structure that organizes them.

${ }^{14}$ In a political economy extension, different constituencies and redistributive policies should be taken into account.

${ }^{15}$ In a very useful recent paper, Hall et al. (2010) model growth where institutions affect growth via their effect on the productivity of (physical and human) capital and provide empirical support for this proposition. However, their study takes institutions as given and also does not distinguish between formal and informal aspects.

${ }^{16}$ Granville and Leonard (2010) provide recent empirical evidence, based on the 89 regions of the Russian Federation, that technology is endogenous to informal institutions.
} 
simplistic, though it not only serves for mathematical tractability but it is also consistent with the many conceptions of institutions.

$F$ and $N$ can be viewed as index numbers that range between 0 and 1 (or some upper and lower values such as $\underline{F}<F<\bar{F}$ and $\underline{N}<N<\bar{N}$ ), where 1 represents the highest quality of an institutional attribute. ${ }^{17}$ Total factor productivity $(A)$ increases in both $F$ and $N$, but at a decreasing rate.

Informal institutions evolve according to the process:

$$
N_{t+1}=N_{t}+g\left(k_{t}\right), \quad \text { where } g^{\prime}>0 ; g<0,
$$

which indicates that $N$ progresses with the level of per capita capital, in lines with the endogenous growth literature. Hence the progression of $N$ exhibits learning by doing; the higher the level of capital, the higher the quality or level of norms that amass with it, defining a higher level of technology. The equation can also be written as: $N_{t}=N_{O}+\sum_{i=1}^{t} g\left(k_{t-i}\right)$, implying that the quality of norms at any given time is given by an initial level of norms that is augmented by the "stock of know-how" accumulated over time.

Capital per labor evolves according to the standard law of motion:

$$
k_{t+1}=(1-\delta) k_{t}+I_{t}
$$

where $\delta$ is the rate of depreciation and $I_{t}$ is the level of investment at time $t .{ }^{18}$ Without loss of generality, it can be further assumed that population growth is zero and hence investment is equal to the savings minus depreciation allowance, such that $I_{t}=s y_{t}-\delta k_{t}$, where $s$ is the savings rate. ${ }^{19}$

Amending formal institutions, or changing the production technology, involves costs coined as creative destruction, along with its projected benefits. Hence, the incumbent government chooses $F$ to maximize output, net of the cost of changing $F$. These costs may be in the form of increased welfare spending to accommodate the labor that becomes idle as a result of the newly adopted technologies or modified organizational structures. ${ }^{20}$ The extent of these costs tends to be related positively with the magnitude of a change in $F$, and negatively with the prevailing distance between $F$ and $N .{ }^{21}$ The first of these effects arises since each level of $F$ is likely to be associated with certain special interest groups who may resist its change. If one considers that $N$ represents the encompassing interests in a society, however, the closer $F$ is to $N$, the less socially necessary or economically efficient would be a change in $F$; hence, the less would there be political support for a change in $F$. Hence, the closer $F$ is to $N$, the greater the cost of changing $F$. In view of the above, the government's problem can be written as:

$$
\operatorname{Max}_{F} y-C\left(\Delta F, \frac{F}{N}\right) ; \quad \text { where } C_{1}^{\prime}>0 \text { and } C_{2}^{\prime}>0
$$

The mechanics of endogenous institutional change can be summarized as follows: the level of output, and thus savings, determines the level of capital accumulation, which in turn leads $N$ to evolve via learning by doing. In each period, the government optimally chooses $F$ to maximize the net benefit given by Eq. (4). The model implies that while an increase in $k$ leads $N$ to increase and in turn affects the optimal choice of $F, F$ affects the level of $N$ through its affect on $y$. Hence, $F$ and $N$ interact continuously, reflecting implicitly that the cost of changing $F$ hinges upon the state of collective action. Hence, although higher values of $F$ may reduce transaction costs and therefore increase output, they may not be optimal for a government to increase $F$.

\footnotetext{
17 The literature provides many examples of quantification of institutional quality on an ordinal scale. See, for example, Central Bank Independence Indices (Cukierman et al., 1992, 2002); Corruption Perception Index (Transparency International), Economic Freedom of the World Index; and Governance indices (the World Bank), to name a few amongst the many.

${ }^{18} \mathrm{I}$ assume full investment efficiency in the sense that all investment spending becomes an addition to the capital stock.

${ }^{19}$ Capital accumulation may also be considered to involve a shock term such that $k_{t+1}=(1-\delta) k_{t}+I_{t}+e_{t}$, where a large $e_{t}$ stands for a major leap in the capital/labor ratio due to either destruction of some productive forces, in instances such as war or natural disasters or as a result of major technological innovations. Significant changes in the structure of production are also often associated with significant changes in the power structure and hence have important political implications. Transition from feudalism to capitalism and socialism entailed such mass transformations from extensive to intensive labor use and the Industrial Revolution.

${ }^{20}$ Moscoso-Boedo (2010) incorporates these costs into the laws of motion of the physical and skilled worker stocks.

${ }^{21}$ In a political economy extension, these costs can be defined as the weighted sum of the costs incurred by different constituencies.
} 
The above dynamics can be summed up by the following sequential pattern:

(i) Given $N_{t}$ and $F_{t}, k_{t}$ depreciates each period while new capital accumulates due to savings that are fully turned into investments.

(ii) $N_{t+1}$ evolves with $k_{t}$.

(iii) Based on the levels of $k_{t+1}$ and $N_{t+1}$, as well as the ratio of $F_{t}$ to $N_{t}$ in the current period, optimal $F_{t+1}$ is selected to maximize $y_{t+1}-$ if optimal $F_{t+1}$ is higher than $F_{t}$, and less than $N_{t+1}{ }^{22}$

\subsection{Simulations}

In order to obtain explicit solutions for the model and to simulate the trajectory of optimal $F$, Eqs. (5)-(8) are considered in place of Eqs. (1)-(4). The government solves the following problem, where the production function is given by $\left(F_{t+1} \cdot N_{t+1}\right)^{\theta} \cdot k_{t+1}^{\beta}$ :

$$
\operatorname{Max}_{F t+1}\left(F_{t+1} \cdot N_{t+1}\right)^{\theta} k_{t+1}^{\beta}-C\left(\Delta F_{t}, N_{t+1}\right)
$$

where the technology exhibits complementarity between $F$ and $N$ such that (for $F<N$ ), total productivity gets higher the closer the values of $F$ and $N$ ).

The cost function is given by:

$$
C\left(\Delta F_{t}, N_{t+1}\right)=\alpha\left(F_{t+1}-F_{t}\right)\left(\frac{F_{t}}{N_{t}}\right), \quad \text { where } \alpha>0
$$

In addition, the law of motion for $N$ and $F$ is given by Eqs. (7) and $(8)^{23}$ :

$$
\begin{aligned}
& N_{t+1}=N_{t}+N_{t}^{\left[1 /\left(100-\log \left(k_{t}\right)\right]\right.} \\
& k_{t+1}=s\left(F_{t} \cdot N_{t}\right)^{\theta} k_{t}^{\beta}+(1-\delta) k_{t}, \quad \text { where } 0<s, \theta, \beta, \delta<1 .{ }^{24}
\end{aligned}
$$

It is further assumed that $F_{t+1}>F_{t}$ and $F_{t+1} \leq N_{t+1}$. The former of these assumptions is made on the grounds that, usually, the formal changes are justified and approved if they imply some improvement over the existing ones; even though the opposite case may exist in reality, the current study does not address it as it is rare. The second assumption, in a way, represents status-quo bias; if $F$ is let to exceed $N$, it would distort the existing ones and generate its own new interest groups.

After substituting (6) in (5), the solution of the problem given by Eq. (5) yields the following optimal path for $F_{t+1}$ :

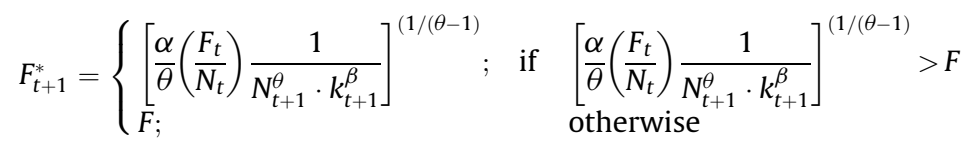

Hence, the solution of the above problem satisfies Eqs. (5), (6) and (9). Given the initial values of $N$ and $F$, the values of $N, F, k$, and $y$ can thus be simulated to yield a dynamic path.

Fig. 1 shows the simulations of $F^{*}$ and $k$ using a set of reasonable parameter values for $\delta, \beta$ and $s .{ }^{25}$ The figure is based on $\alpha=50$ and $\theta=0.5$, although different values of these parameters lead to similar patterns. ${ }^{26}$ The initial capital intensity is normalized to 1 . The figure has three panels corresponding to three different sets of initial $F$ and $N$ values that are considered to proxy different development scenarios. To be able to focus solely on the differences in trajectories that arise from different initial

\footnotetext{
${ }^{22}$ The last assumption can be made based on the endogenous evolution of $F$, in which case the demands of interest groups are limited by the level of $N$.

${ }^{23}$ The functional form given in Eq. (7) is chosen to obtain a smooth progression for $N$.

24 Simulations yield reasonable results for $\theta \leq 0.96$.
} 
I :I nitial $N=0.3$ and Initial $F=0.1$
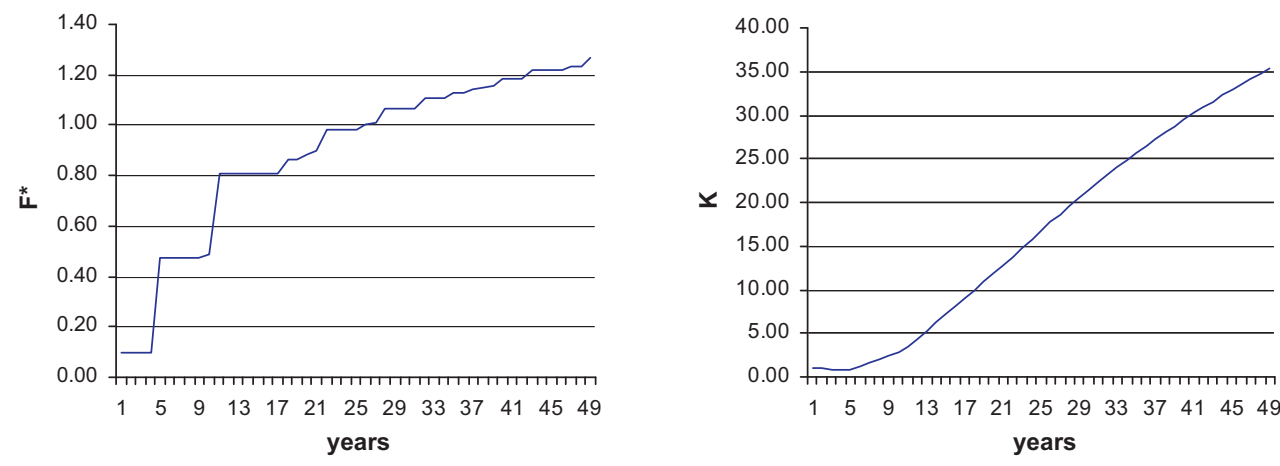

II. Initial $N=0.7$; I nitial $F=0.5$
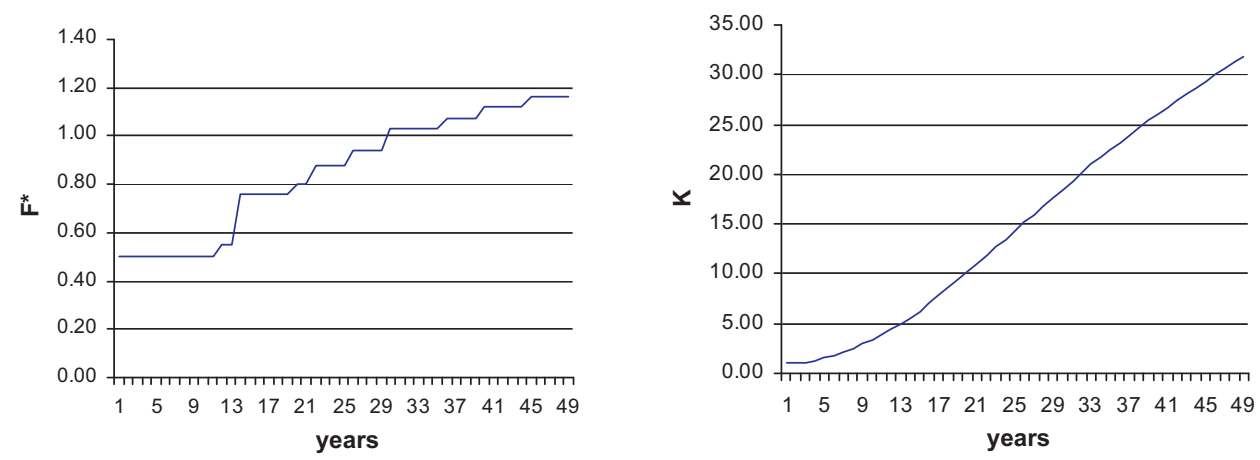

III. Initial $N=0.7$; I nitial $F=0.2$
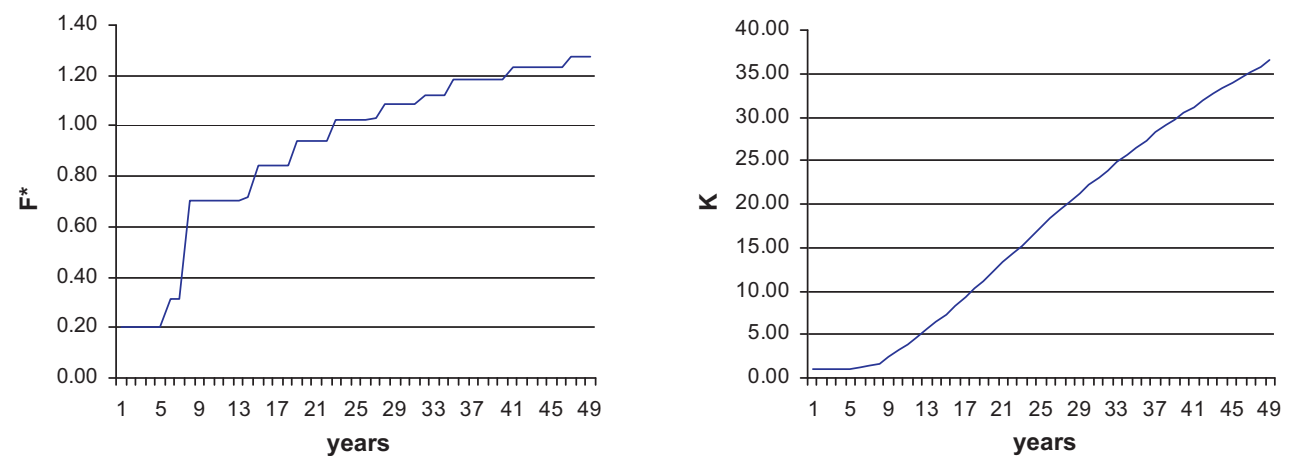

Fig. 1. Trajectories (50 years) of $F^{*}$ and $k$ (assuming $k=1 ; \alpha=100 ; \beta=0.2 ; \delta=0.08 ; \theta=0.8$ and $s=0.2$ ). 
values of institutions, the rest of the parameter values and variable calibrations are kept constant across different scenarios.

The first panel in Fig. 1 represents the case of developing countries that have low levels of institutional development, with less than 0.5 initial values for $F$ and $N$. The second represents developed countries, where both types of institutional indices are relatively high $(F=0.5$ and $N=0.7)$, and the third one developed countries where norms are developed but formal institutions are not, where $F$ and $N$ are taken to be 0.2 and 0.7 respectively. For this last case, one could consider the 2007 crisis that pointed at the need of substantial reforms for the financial institutions of developed countries. One can observe clearly, based on all the panels in Fig. 1, that the trajectories of $F^{*}$ reflect a punctuated nature. In addition, a comparison of the levels to which $F^{*}$ and $k$ converge in all three panels indicates that convergence may be realized and the poverty-trap may be avoided in the case of continuous institutional reforms, even when institutions are low quality to start with.

Observation 1. The optimal path of formal institutional reform depicts a punctuated pattern.

To test the sensitivity of the results to the model parameters, greater $k$ and $\beta$ values are chosen to represent developed countries. Although these modifications leave the nature of the results virtually the same, it is observed that higher $k$ slows down the reforms, whereas higher $\beta$ appears to lead to faster updates of $F^{*}$. In addition, convergence is observed to be reached across different values of $k$, keeping the rest of the model parameters and initial $F$ and $N$ values the same.

Observation 2. Income convergence can be achieved via institutional development.

Further simulations are performed to examine the sensitivity of the reported findings to the model parameters. ${ }^{27}$ Keeping other parameters constant, it is observed that lower values of $\theta$ generally lead to lower steady-state values and more prolonged periods before a change in $F^{*}$ occurs (except for $N>0.5$ ). The effect of $\theta$ on $F^{*}$ gets weaker as the values of income share of capital $(\beta)$ get bigger. The positive relationship between $\beta$ and $F^{*}$ also gets weaker the greater $\beta$ is. In addition, the negative relationship between the cost of changing $F(\alpha)$ and $F^{*}$ increases as $\beta$ increases. The following partial derivatives summarize these observations that are all in line with expectations. ${ }^{28}$

$$
\begin{array}{lll}
\frac{\partial F^{*}}{\partial \alpha}<0 ; & \frac{\partial F^{*}}{\partial \beta}>0 ; & \frac{\partial F^{*}}{\partial \theta}>0 ; \\
\frac{\partial^{2} F^{*}}{\partial \alpha \cdot \partial \alpha} \approx 0 ; & \frac{\partial^{2} F^{*}}{\partial \beta . \partial \beta}<0 ; & \frac{\partial^{2} F^{*}}{\partial \theta \cdot \partial \theta}\left\{\begin{array}{l}
>0 \ldots \text { if } \theta<0.8 \\
<0 \ldots \text { otherwise }
\end{array} ; \quad\left|\frac{\partial^{2} F^{*}}{\partial \alpha \partial \beta}\right|<0 ;\right. \\
\frac{\partial^{2} F^{*}}{\partial \beta \cdot \partial \alpha} \approx 0 ; & \frac{\partial^{2} F^{*}}{\partial \theta \cdot \partial \alpha} \approx 0 ; & \frac{\partial^{2} F^{*}}{\partial \beta \cdot \partial \theta}\left\{\begin{array}{l}
>0 \text { if } \theta<0.8 \\
<0 \ldots \text { otherwise }
\end{array}\right.
\end{array}
$$

As the above comparative statics indicate, the cost of changing $F$ does not affect the responsiveness of optimal $F$ to the income shares of technology and capital. In addition, as expected, the effects of $\alpha, \beta$ and $\theta$ on $F^{*}$ generally increase in $\theta$ and decrease in $\beta$. Simulations further show the complementarity between $N$ and $F$; the output effect of $N$ increases in $F$ and vice versa, for all levels of institutional development. ${ }^{29}$ It is also observed that the contributions of both $N$ and $F$ on output increase in $\beta$, although at a decreasing rate. Based on these observations and implied trajectories of the model, the following observations can be made.

\footnotetext{
${ }^{25}$ Nadiri and Prucha (1996) show that the depreciation rate for physical capital is 0.06 and for R\&D is 0.12 for the US. In addition, Mankiw et al. (1992) show that $\beta=1 / 3$ for US. According to the World Development Indicators database of the World Bank, the world average of the saving rate (gross savings as percentage of GNI) has been between 0.20 and 0.23 during the past three decades.

${ }^{26}$ Simulations based on alternative parameter values are available from the author upon request.

27 The data and graphs are available upon request.

${ }^{28}$ The comparative static results are obtained using the MATLAB program and simulations.
} 
Observation 3. Assuming a CRTS production function, the smaller the income share of capital, the more gradual is the progression of $F^{*}$.

Observation 4. The negative effect of the cost of formal reforms $\left(\partial F^{*} / \partial \alpha\right)$ is mitigated by the increase in the income share of capital or technology (for $\theta<0.2$ ).

The last two propositions help to explain why the convergence between less developed and developed economies take a long time to occur. A focus on the reduction of the cost of formal reforms in less developed countries therefore appears to be an important policy issue.

Appendix 1a shows the trajectories of optimal- $F$ and $k$ in relation to $\theta$ and $\alpha$. The graphs indicate that, even though both variables follow an upward trend for a range of $\theta$ values, the cost of reform lowers these trajectories severely. Appendix 1b shows that increasing the contribution of $F$ on productivity (especially for $\theta>0.8$ ) substantially increases the long-term optimal capital.

Since $N$ accumulates continuously, it may have increasing returns. To account for such a possibility, I also explored the following form of the production function: $\left(F_{t+1}^{\theta 1} \cdot N_{t+1}^{\theta 2}\right) \cdot k_{t+1}^{\beta}$, where $\theta_{2}>0$. While the trajectories in this case indicate only a slightly more upward trend, the basic observations on the trajectories remain virtually unchanged.

\subsection{Evidence}

Institutional change is a continuous process and concerns not only developing but also developed countries. The implications of the above model can indeed be exemplified in the attempts of many developed nations' governments to revise their financial regulatory and supervisory frameworks in the aftermath of the 2007 global financial crises. ${ }^{30}$ The recent crisis revealed the necessity for $F$ to catch up with $N$ in the financial sector, where $N$ in this case represents the increased risk appetite in financial transactions and rapidly developing financial engineering tools in a generally prospering global environment, and $F$ represents the regulatory framework that needs reform so as to reduce or eliminate the transaction costs related with the usage of those tools. Crises are among the primary factors that trigger institutional change; they are also observed to lead to paradigm shifts or cycles in economic thinking. Since foreseeing the dynamic interactions between institutions and economic development is not fully possible, however, neither is reforming institutions once and for all to insure against all potential economic risks.

As each formal institution may interact with a different set of informal institutions and hence affects development through various direct or indirect channels, providing an empirical exploration of the models' predictions is beyond the scope of the current paper. ${ }^{31}$ Instead, this paper paves the way for such research by drawing attention to the evidence regarding the evolution of some welldocumented formal institutional measures that support the current model's predictions.

Williamson (2009) points out that measuring $F$ is rather difficult as many indicators are the outcomes of institutions rather than the institutions themselves (among them she counts the governance indicators of Kaufmann et al. and the ICRG index). In view of this, Williamson and Kerekes (2011) follow Gleaser et al. (2004) and take into account the constraints on the executive, judicial independence and constitutional review to measure $F^{32}$ Sobel and Coyne (2011) also use the constraints on the executive, democracy and autocracy (Polity IV measures of Marshall et al., 2011) to measure $F$. Most of these variables, however, are not available on a time-series basis and hence cannot be employed to observe an evolutionary pattern of the sort investigated above. The variable that is available on a time-series basis

\footnotetext{
${ }^{29}$ This is in contrast with Ahlerup et al. (2009) finding of substitutability between formal institutions and social capital. However, the example that Ahlerup et al. provide on the smaller the effect of $N$ the higher the income level is confirmed by the current model.

${ }^{30}$ In a related study, Van de Klundert (2010) models institutional change as recurrent waves in the case of a capitalist society.

${ }^{31}$ A research in that spirit is provided by Posen (1995) in the context of central bank independence, where the author argues that it is not the central bank law, but the underlying financial consensus that may also lead to the adoption of the law, that matters for the outcome of price stability.
} 

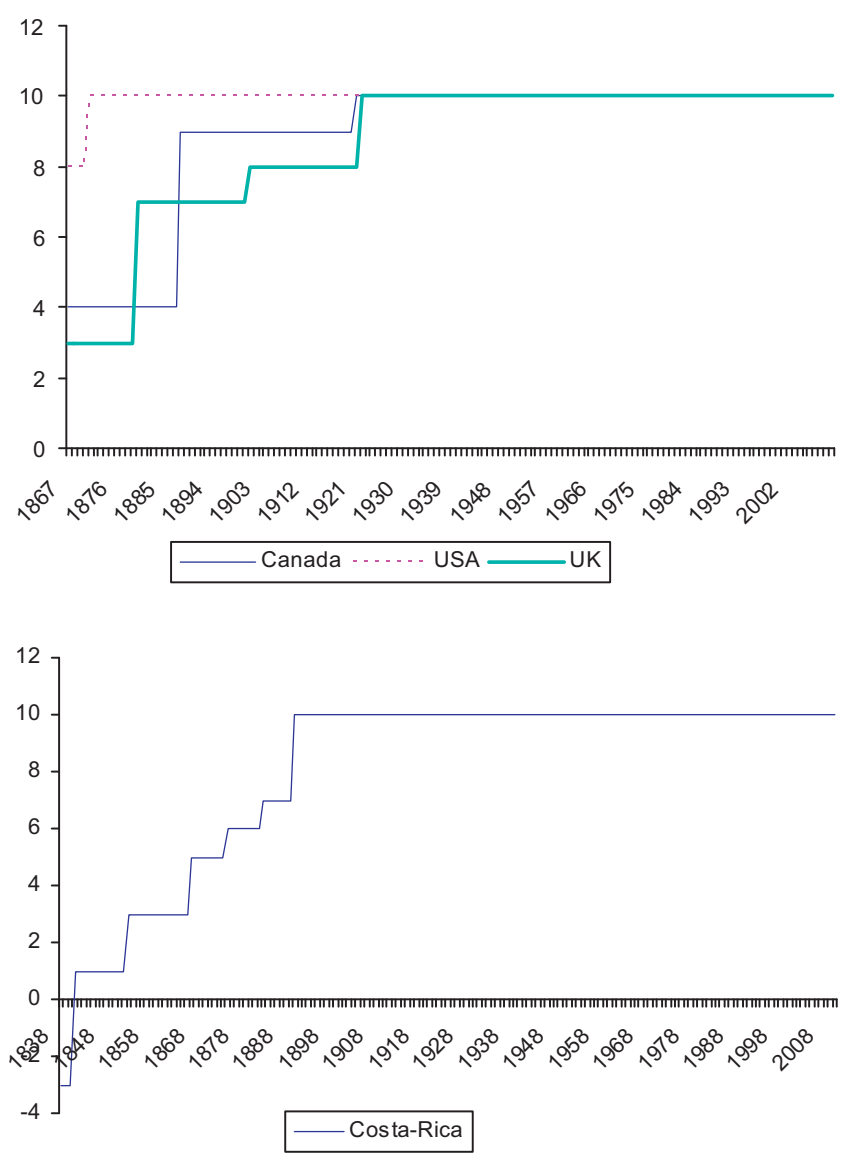

Fig. 2. Polity2 indices for a sample of countries.

Source: Marshall et al. (2011).

and appears to be the closest candidate to measure the status of formal institutions in a macroeconomic sense is therefore the Polity IV variable. ${ }^{33}$ Fig. 2 demonstrates the evolution of this variable in a sample of select democracies for a span of more than a century, supporting the pattern predicted in the model described in the previous section and in Fig. 1. It should be noted that the upward but punctuated pattern that the current model conjectures assumes away, for simplicity of the analysis, the effects on institutions of disruptions caused by extraordinary economic or political episodes. ${ }^{34}$ In addition to developed country examples, the figure also shows that Costa Rica, an exceptional developing country with a stable democratic regime, provides an example for an upward punctuated pattern of Polity IV index since the early 1800 s. $^{35}$

\footnotetext{
32 Tabellini (2010) uses the World Values Survey (WVS), and Williamson and Mathers (2011) focus, in particular, on the trust, self-determination, respect and obedience aspects of WVS for measuring $N$. The WVS dataset, however, has lags in the time-series reported for each country; hence this section does not report evidence on the pattern of $N$, but focuses on the evolutionary process of $F$.

33 Polity IV is an index ranging between -10 and 10 , which measures the extent of autocracy/democracy.
} 

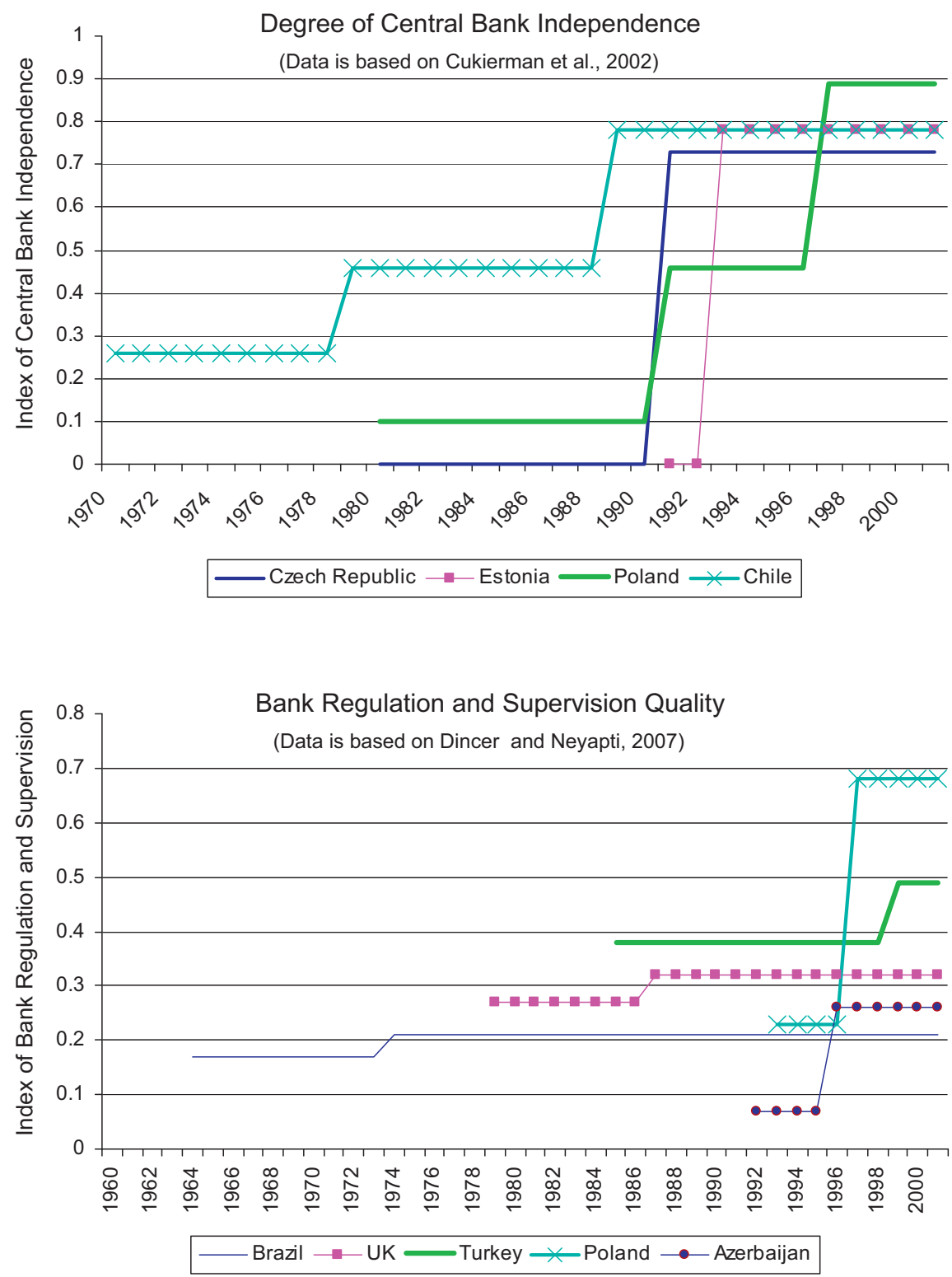

Fig. 3. Sample trajectories of institutional reforms: some evidence.

In the following, the evolutionary pattern of specific monetary institutions, for which legal measurements are available, is presented. Fig. 3 shows sample trajectories of central bank independence (CBI) and bank regulation and supervision (RS). The first of these graphs demonstrates

\footnotetext{
${ }^{34}$ Unlike the continuous, though punctuated, upward pattern in the Polity IV index observed in Canada, UK and the USA, the index is observed to fall in Germany and France during World War II, but catching up with those reported above shortly after. Likewise, because many developing countries have had intermittent periods of autocratic regimes, an upward evolutionary pattern is not observed in those over a long period going back in history.
} 
the changes in CBI in three formerly centrally planned economies and Chile. In this graph, while CBI in Chile shows a continual progression, $\mathrm{CBI}$ in transition economies shows abrupt changes pursuant to the wide-ranging market reforms that followed major political overhauls. It can be argued that the cost of modifying formal mechanisms became much easier for transition countries that underwent major changes in the political power structures accompanying economic crises. The upper graph of Fig. 2 also provides examples in support of institutional convergence.

The lower graph of Fig. 3 demonstrates much slower changes in Brazil and the UK with regard to RS than in transition countries. In line with the previous, a possible explanation for this observation could be the existing interest group resistance to a change in the status quo in the former two countries, in contrast with the transition countries that revised their legal frameworks following severe crises whose effects were all-encompassing. Contrary to the upper graph of Fig. 3, however, the different levels of RS observed in different countries probably indicate that many countries are still far away from the steady-state level of RS. In other words, comparing the two graphs seems to exemplify the fact that while the high or hyperinflationary episodes that caused great welfare losses during the past decades have led the central bank reforms to have been widely achieved around the world, there still seems to be a long way to go with regard to the reforms in the financial and banking sectors in many countries.

\section{Concluding remarks}

This study proposes an original formal model of endogenous institutional change vis à vis economic growth. Technology comprises two attributes that affect productivity and transaction cost reduction: informal ways of conducting business, or norms, and formal institutions that regulate, supervise and enforce those conducts. While informal institutions continuously evolve as a result of technological know-how, formal institutions change via governments' optimizing behavior and usually follow a punctuated pattern. This pattern stems from the creative destruction that institutional change, as any technological change, may lead to; such destruction is due to economic and political costs incurred by

\footnotetext{
${ }^{35}$ Costa Rica stands out as an example of an undisrupted pattern of evolution and hence it would not be appropriate to evaluate, based on this single observation, the relevance of the observations made earlier in this paper with regard to developing country performance.
} 

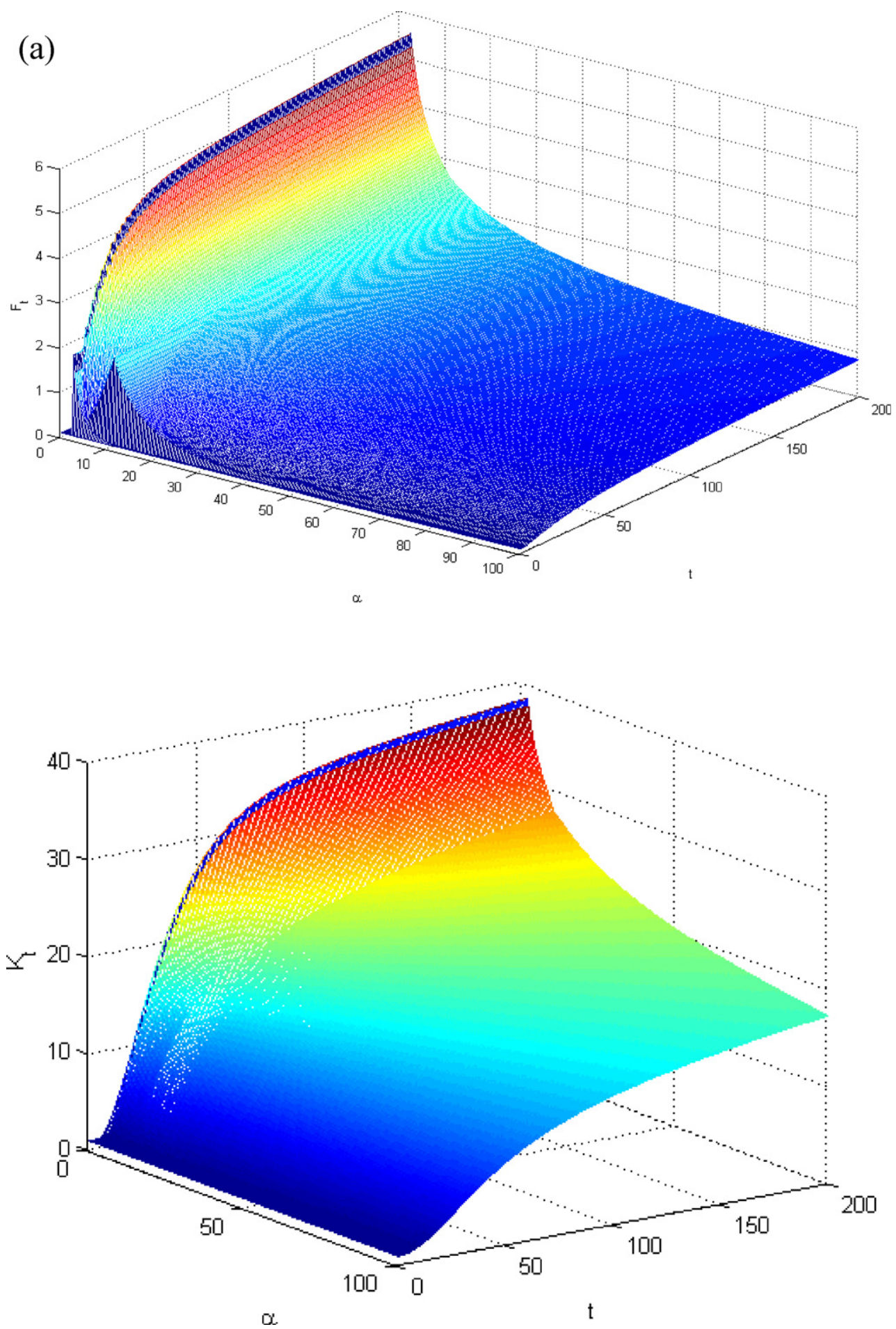

Fig. A1. Sample trajectories of $F^{*}$ and $k$ over time and $\alpha$ (given initial values and model parameters: $F_{0}=0.1 ; N_{0}=0.5 ; k_{0}=1$; $\delta=0.08 ; s=0.2 ; \beta=0.3 ; \alpha=50)$. 
(b)
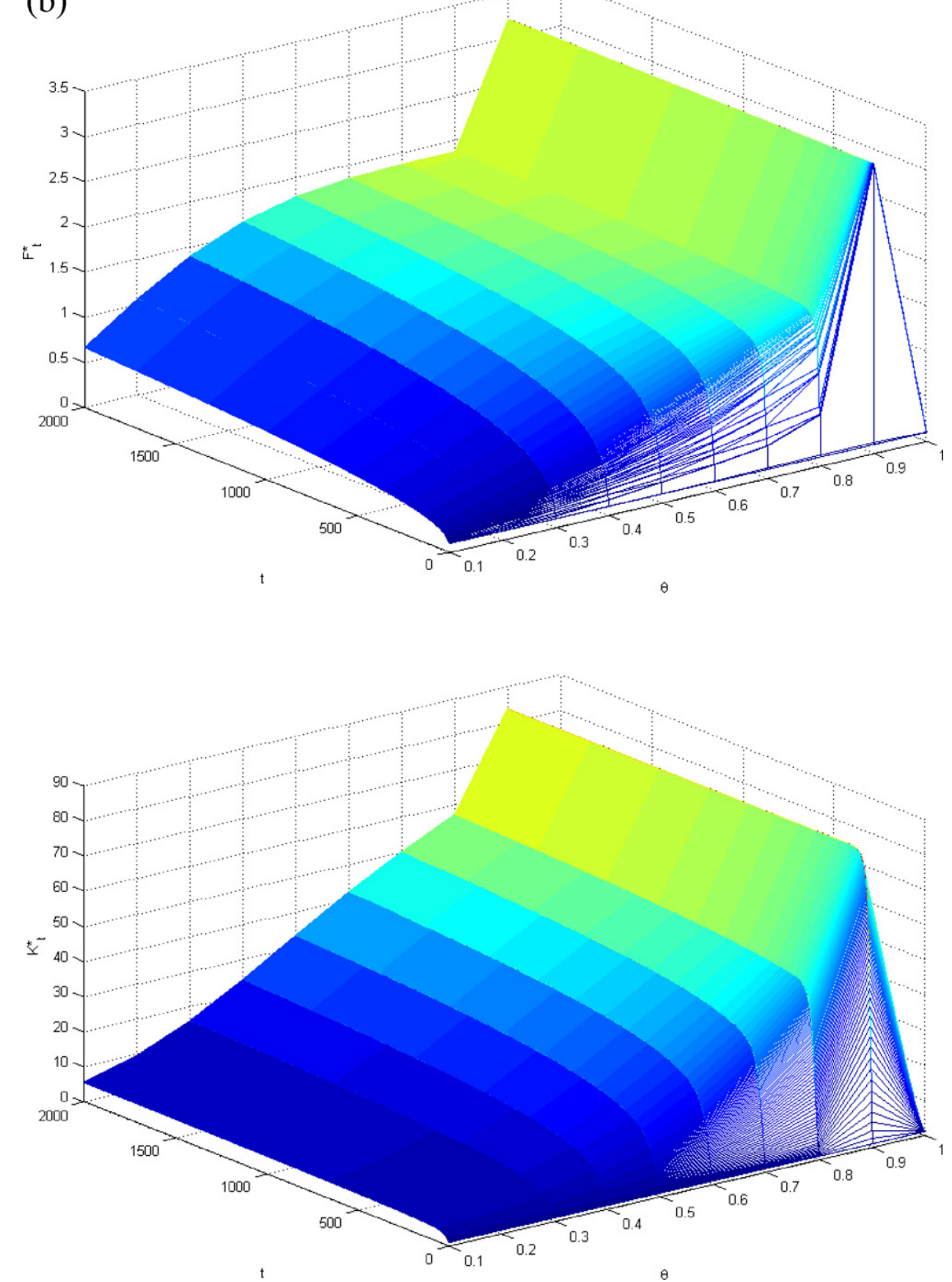

Fig. A2. Sample trajectories of $F^{*}$ and $k$ over time and $\theta$ (given initial values and model parameters: $F_{0}=0.1 ; N_{0}=0.5 ; k_{0}=1$; $\delta=0.08 ; s=0.2 ; \beta=0.3 ; \alpha=50$ ). 
prevailing interest groups. Hence, the model is consistent with the two main strands of institutional approaches: transaction cost and collective action theories. Simulations of the model reveal a punctuated pattern of evolution for formal institutions. In addition, income convergence seems to be achieved via institutional development. The findings are consistent with the evidence on the evolutionary pattern of some observed measures of formal institutional change, namely the Polity2 index, central bank independence and bank regulation and supervision quality.

\section{Acknowledgements}

I am very grateful for the comments of Esra Durceylan, Cagri Saglam and Zeki Sarigil. I am also indebted to two anonymous referees for their invaluable comments and suggestions. Last but not least, I thank M. Kerem Yuksel for his excellent research assistance.

\section{Appendix 1}

See Figs. A1 and A2.

\section{References}

Acemoglu, D., 2006. A simple model of inefficient institutions. Scandinavian Journal of Economics 108, 515-546.

Ahlerup, A., Olsson, O., Yanagizawa, D., 2009. Social capital vs institutions in the growth process. European Journal of Political Economy 25, 1-14.

Aron, J., 2000. Growth and institutions: a review of the evidence. World Bank Research Observer 15, 99-135.

Boettke, P.J., Coyne, C.J., Leeson, P.T., 2008. Institutional stickiness and the new development economics. American Journal of Economics and Sociology 67, 331-358.

Clarke, G.R., 2001. How institutional quality and economic factors impact technological deepening in developing countries. Journal of International Development 13, 1097-1118.

Coase, R., 1960. The problem of social cost. Journal of Law and Economics 3, 1-44.

Coates, D., Heckelman, J.C., 2003. Interest groups and investment: a further test of the Olson hypothesis. Public Choice 117, 333-340.

Coates, D., Heckelman, J.C., Wilson, B., 2010. The political economy of investment: sclerotic effects from interest groups. European Journal of Political Economy 26, 208-221.

Coates, D., Heckelman, J.C., Wilson, B., 2011. Special-interest groups and growth. Public Choice 147, 439-457.

Cukierman, A., Webb, S., Neyapti, B., 1992. Measuring the independence of central bank and its policy outcomes. World Bank Economic Review 6, 353-397.

Cukierman, A., Miller, G., Neyapti, B., 2002. Measuring the independence of central bank and its policy outcomes. Journal of Monetary Economics 49, 237-264.

Dollar, D., Kraay, A., 2003. Institutions, trade and growth. Journal of Monetary Economics 50, 133-162.

Dincer, N., Neyapti, B., 2008. What affects the quality of bank regulation and supervision? Contemporary Economic Policy 26 , 607-622.

Easterly, W., Levine, R., 2003. Tropics, germs and crops: how endowments influence economic development. Journal of Monetary Economics 50, 3-39.

Eldredge, N., Gould, S., 1972. Punctuated equilibria: an alternative to phyletic gradualism. In: Schopf, T.J. (Ed.), Models in Paleobiology. Freeman, Cooper \& Co., San Francisco, pp. 82-115.

Gersick, C.J.G., 1991. Revolutionary change theories: a multilevel exploration of the punctuated equilibrium paradigm. The Academy of Management Review 16, 10-36.

Gleaser, E., La Porta, R., Lopez-de Silanes, F., Schleifer, A., 2004. Do institutions cause growth? Journal of Economic Growth 9 , $271-393$.

Granville, B., Leonard, C.S., 2010. Do informal institutions matter for technological change in Russia? The impact of communist norms and conventions, 1998-2004. World Development 38, 155-169.

Hall, J.C., Sobel, R.S., Crowley, G.R., 2010. Institutions, capital and growth. Southern Economic Journal 77, 385-405.

Heckelman, J., 2007. Explaining the rain: the rise and decline of nations after 25 years. Southern Economic Journal 74, 18-33.

Kaufmann, D., Kraay, A., Mastruzzi, M., 2009. Governance Matters VIII: Aggregate and Individual Governance Indicators, $1996-$ 2008. World Bank Policy Research Papers 4978. The World Bank, Washington, DC.

Kemmerling, A., Neugart, M., 2009. Financial market lobbies and pension reform. European Journal of Political Economy 25, 163-173.

Knack, S., Keefer, P., 1995. Institutions and economic performance: cross-country tests using alternative institutional measures. Economics and Politics 7, 207-227.

Mahoney, J., 2000. Path dependence in historical sociology. Theory and Society 29, 507-548.

Mankiw, N.G., Romer, D., Weil, D.N., 1992. A contribution to the empirics of economic growth. Quarterly Journal of Economics 107, 407-437. 
Marshall, M.G., Jaggers, K., Gurr, T.R., 2011. Polity IV Project. Center for Systemic Peace. University of Maryland, College Park, MD.

Mathers, R., Williamson, C.R., 2011. Cultural context: explaining the productivity of capitalism. Kyklos 64, 231-252.

Moscoso-Boedo, H., 2010. Optimal technology and development. Journal of Macroeconomics 32, 617-634.

Nabli, M.K., Nugent, J.B. (Eds.), 1989. The New Institutional Economics and Development: Theory and Applications to Tunisia. North Holland, New York.

Nadiri, M.I., Prucha, I.R., 1996. Estimation of the depreciation rate of physical and R\&D capital in the U.S. total manufacturing sector. Economic Inquiry 34, 43-56.

Neyapti, B., Dincer, N., 2005. Measuring the quality of bank regulation and supervision, with an application to transition economies. Economic Inquiry 43, 79-99.

North, D., 1990. Institutions, Institutional Change and Economic Performance. Cambridge University Press, Cambridge, MA.

Olson, M., 1965. The Logic of Collective Action: Public Goods and the Theory of Groups, Revised ed. Harvard University Press, Cambridge, MA.

Olson, M., 1982. The Rise and Decline of Nations: Economic Growth, Stagflation and Social Rigidities. Yale University Press, New Haven, CT.

Pierson, P., 2000. Increasing returns, path-dependence and the study of politics. American Political Science Review 94 , 251-267.

Roland, G., 2004. Understanding institutional change: fast-moving and slow-moving institutions. Journal of Comparative International Development 38, 101-131.

Sobel, R.S., Coyne, C.J., 2011. Cointegrating institutions: the time-series properties of country institutional measures. Journal of Law and Economics 54, 111-134.

Tabellini, G., 2010. Culture and institutions: economic development in the regions of Europe. Journal of the European Economic Association 8, 677-716.

Van de Klundert, T., 2010. On the determinants of institutional design. European Journal of Political Economy 26, $167-175$.

Williamson, C.R., 2009. Informal institutions rule: institutional arrangements and economic performance. Public Choice 139, $371-387$.

Williamson, C.R., Mathers, R., 2011. Economic freedom, culture and growth. Public Choice 148, 313-335.

Williamson, C.R., Kerekes, C., 2011. Securing private property: formal versus informal institutions. Journal of Law and Economics 54, 537-572.

Williamson, O.E., 1985. The Economic Institutions of Capitalism. The Free Press, New York.

Yao, Y., 2004. Political process and efficient institutional change. Journal of Institutional and Theoretical Economics 160, 439-453. 